\title{
A IMPORTÂNCIA DE CONHECER PARA ENTÃO CONVIVER COM A CRIANÇA QUE POSSUI TRANSTORNO OPOSITOR DESAFIADOR - TOD
}

\author{
Marcelane Aparecida Ferreira \\ Pedagoga, Mestre em ciências da Educação pela Universidade Gama Filho-RJ (Brasil) \\ Marcelane.ferreira3@gmail.com
}

\begin{abstract}
Resumo: Quando uma criança é muito desafiadora, opositiva e não se entende a causa de suas atitudes, provavelmente essa criança poderá ter "Transtorno Opositivo Desafiador". Essas crianças costumam ser deixadas de lado pelas outras crianças e a família, perdem oportunidades e desfazem círculos de amizades, pois, aos olhos dos colegas se tornam uma ameaça agressiva; os pais acabam por evitar sair com sua criança devido o mau comportamento e desobediência. O problema de pesquisa ao qual surgiu interesse pelo tema esta pautado no questionamento problematizador: A falta de conhecimento sobre este transtorno pode levar ao entendido superficial, como falta de limites, hiperatividade ou desobediência, e/ou ser confundido também com outros tipos de transtornos, pode dificultar o convívio escolar? Nosso objetivo geral é conhecer as características do transtorno opositor desafiador e suas influências na escola, diretamente na sala de aula e importância do tratamento. Este artigo tem como metodologia a pesquisa bibliográfica, sugere que pode haver um conjunto de aspectos biológicos, psicológicos e social que influenciam no surgimento do transtorno na criança. Porém, ainda são necessários mais estudos correlatos. Esse transtorno leva a criança, a uma grave dificuldade para avaliar e entender e aceitar opiniões alheias, apesar de ser intolerante às suas frustrações, pois não aceitam ser desapontado, levando-o a atitudes intempestivas, sem qualquer diplomacia ou controle emocional. Tal transtorno é caracterizado por um padrão repetitivo da conduta antissocial sendo marcado pela agressividade e violação das normas sociais; que visto pelo olhar pedagógico, pode ser dito como, falta de limite. É importante e responsabilidade de todos os atores envolvidos, conhecer, para compreender e aprender como agir e conviver com essas crianças, a fim de torná-las mais apáticos e também se sentirem mais compreendidos e amados. Várias questões sobre o TOD foram enfatizadas nesta pesquisa, uma delas foi mostrar a grande importância de se conhecer melhor o Transtorno Desafiador Opositor.
\end{abstract}

Palavras chave: Transtorno Opositor; Desafiador; Dificuldade; Agressividade; Apatia.

\section{INTRODUÇÃO}

$\mathrm{Na}$ composição deste artigo, focalizamos a descrição e discussão das atitudes agressivas em diagnósticos de Transtorno Desafiador Opositor, consiste em um transtorno psicológico caracterizado, principalmente, por comportamentos 
apresentados pela criança no sentido de agir contrariamente àquilo que se pede ou se espera dela, dentro da sala de aula e/ou em convivência com outros ambientes.

A metodologia utilizada para a realização desta pesquisa, sobre transtorno opositor desafiador é a pesquisa bibliográfica. Através de levantamento de livros, monografias, dissertações, teses, artigos, periódicos sobre o tema, na qual serviu de base para a especificidade do tema abordado como necessidade para conhecer mais a fundo nossos alunos com esse tipo de transtorno. Além de ser um modo essencial para realizar os estudos inerentes à redação desta pesquisa, porque nos auxilia em trilhar na busca de conhecer o que de mais inerente e citado tem sido produzido sobre este tema.

A problemática é: A falta de conhecimento sobre este transtorno pode levar ao entendido superficial, como falta de limites, hiperatividade ou desobediência, e/ou ser confundido também com outros tipos de transtornos, pode dificultar o convívio escolar?

Como objetivo geral; conhecer as características do transtorno opositor desafiador e suas influências na escola, diretamente na sala de aula e importância de seu tratamento, enquanto os objetivos específicos são: explorarem as concepções do transtorno opositor desafiador, esclarecer dúvidas quanto ao mesmo, propor algumas alternativas de como trabalhar com esses alunos portadores do transtorno opositor e formas de seu tratamento.

E propor reflexão sobre transtorno opositor desafiador; como enfrentá-lo no dia a dia da escola e em família buscando trazer mais clareza no entendimento sobre o transtorno, ajudar outros pesquisadores, professores e pais tornando este trabalho mais significativo para entender os alunos acometidos desse comportamento e a importância do tratamento, ou seja, para que consiga seguir com uma rotina social normal, no seu processo de aprendizagem, consequentemente melhorarem seu relacionamento com pais, professores, colegas.

Os aspectos do transtorno opositor de desafiador (TOD) estão presentes no Transtorno de Conduta (TC), e não se faz o diagnóstico de TOD se são completos os fundamentos para TC. Levando em consideração a que nos esclarece APA (2002), onde o transtorno de conduta é um quadro mais amplo devido o mesmo também tem todas as características e é mais complexo que o transtorno opositor desafiador. 
As condutas das crianças com transtorno opositor são menos graves que aquelas apresentadas no transtorno de conduta, pois quando chega a se tornar em transtorno de conduta é devido a sua personalidade já esteja formada; eles não chegam a agredir pessoas, nem destruir propriedades, cometer roubos ou defraudação, onde já quem possui transtorno de conduta são capazes de cometer quaisquer destas.

Mas a busca de aprofundar-se no TOD vem por ser um anseio por conhecimento; passar conhecimento a outros profissionais; e necessariamente ao ator principal na sala, que é o professor, onde é quem acompanha e convive mais de perto com estes estudantes no ambiente escolar ao qual estão inseridos.

É perceptível que nem toda a criança consegue se desenvolver física e mentalmente saudável, podendo ter predisposições a outros tipos de doenças, seja ela física ou psicológica, mas que poderão atrapalhar seu desenvolvimento emocional e cognitivo; afetar prejudicialmente também as pessoas que vivem com ela, e também os grupos em que convive, um exemplo, é o grupo escolar, criando situações tensas e difíceis para todos. Segundo Silva (2017):

Um desses problemas é o Transtorno Opositor Desafiador. Ele está dentro dos transtornos neuropsíquicos de comportamento desruptível, que são comportamentos que fazem mal tanto para a criança que tem como para quem convive com ela. $\mathrm{O}$ TOD atinge em média $6 \%$ das crianças e dos adolescentes e esse índice não deve ser desprezado. (SILVA, 2017, pag. 08)

Ainda existem poucos estudos disponíveis que esclareça melhor as dúvidas de quem convive com crianças com Transtorno Opositor Desafiador, a bibliografia estudada sugere que um conjunto integrado de aspectos de natureza biológica, seja geneticamente dos pais e que psicológica e social também podem influir no aparecimento deste transtorno. Contudo, ainda são necessárias mais pesquisas, no sentido de caracterizar o peso ou importância das diferentes variáveis, exemplo disso é o meio familiar e social no qual este convive.

A pesquisa bibliográfica construída foi levantada alguns autores que têm refletido sobre a questão do transtorno opositor desafiador e suas influências na escola, família e ambientes no qual frequentam. Visando a aceitação das hipóteses levantadas neste trabalho, apontando para novas possibilidades em que irá auxiliar no enfrentamento desse transtorno. 
Barros e Silva (2006) afirmam que, no estudo do desenvolvimento de comportamentos agressivos ao longo da infância e adolescência estão sendo alvo de vários questionamentos, questões essas referentes à origem e à manutenção da agressividade durante a trajetória de vida.

Evidenciada pelos autores a necessidade de analisar, o processo de maturidade, onde apresentam comportamentos agressivos, se esses comportamentos se apresentarem de formas grave e frequentes, podendo indicar sinais de psicopatias.

São vários os fatores e situações que podem gerar crenças e estados emocionais, que predispõem às atitudes agressivas, com a revisão da literatura, consideramos vários fatores que predispõem, estresses ou motivos relevantes que podem ser, perca ou ausência de um dos pais; alguém importante da família, brigas no ceio familiar, o nascimento de um irmão, solidão constante ou até o abandono, ser humilhado na escola, mudar de cidade, de casa ou até escola, ou, possuir alguma característica diferente dos demais.

\section{Importância de conhecer e como identificar o Transtorno Opositor Desafiador}

Os primeiros indicativos do transtorno opositivo desafiador aparecem na educação infantil, raramente, mas muito possível na adolescência; alguns comportamentos que podem ser considerado normal em alguns momentos na infância e adolescência, mas quando constantes e excessivos em relação às outras crianças na sua mesma idade.

Crianças que iniciaram com sinais deste comportamento desafiador antes dos seis anos, provavelmente aquelas que receberam o diagnóstico desse transtorno durante a infância tendem em maior probabilidade, a terem atitudes antissociais quando adulto. Além disso, Webster-Stratton \& Hebert (1994), exprime a amplitude do comportamento desviado que é relevante, pois as crianças que apresentam esse tipo de conduta em ambiente escolar e em casa tendem a correr maior risco de serem antissociais.

O "Transtorno Opositor Desafiador" pode estar sendo percebido pela atitude hostil, pode ter reação agressiva ou simplesmente ignorar o que a pedem, assim explica, Caballo e Simon (2015) em sua obra: 
Os comportamentos opositivos podem assumir diversas formas, podendo ser passivos, quando uma criança não responder a um dado estímulo, permanecendo inativa e acomodada, ou desafiadores, incluindo verbalizações negativas, comportamentos hostis e resistência física que incidiriam junto com a desobediência. (CABALLO; SIMÓN, 2015)

Essa disfunção é um transtorno disruptivo onde há a quebra de um processo comportamental que deveria ser normal, do controle pessoal, de impulsos e da própria conduta, ou seja, envolve problemas de autocontrole de emoções e também comportamentos. Luciana Brites, psicopedagoga, uma das fundadoras do Instituto NeuroSaber (2016), explica que a criança tem dificuldade em ter empatia e como lidar com as frustrações e o afeto, não sentindo nenhum tipo de amor ao próximo, muito menos culpa quando faz algo de errado, magoa, ou machuca um colega com seu rompante de agressividade.

O Transtorno Opositor Desafiador consiste em um distúrbio psicológico onde é caracterizado por comportamentos contrários ao que se pedem as crianças, onde elas agem contrariamente àquilo que se espera que ela atenda. Diferentes comportamentos caracterizam o problema como nos esclarece Kaplam, Sadock e Greb (2003) que esse adoecimento consiste em persistentes comportamentos contrários a todos, hostis, desafiadores e insensíveis às normas sociais ou os direitos do próximo.

Os principais transtornos envolvidos com atitudes antissociais ou desafiadores são o Transtorno Opositivo Desafiador (TOD) e o Transtorno de Conduta (TC); onde o TOD caracteriza-se especialmente pela presença de condutas de oposição, desobediência e desafio. Esses comportamentos opositivos e desobedientes podem ser passivos e apáticos, uma vez que a criança pode não responder ao pedido, mas pode apenas permanecer inativa sem também desafiar ou contrariar quem está a sua volta. Luiselle (2005) salienta sobre essas atitudes serem desafiadoras, serem sempre contrários, além de suas verbalizações negativas e/ou agressivas, podendo até a ocorrer junto com a desobediência, a resistência física.

A análise do TOD tem sido um preceptor importante para a evolução do problema ao Transtorno de Conduta, sugerindo que haja um contínuo aumento entre estas duas patologias TOD e TC. A APA (2002) fortalece essa ideia de que o transtorno opositivo desafiador se manifesta até os oito anos de idade e tem poucas 
chances de iniciar no início da adolescência e esses sinais opositivos emergem no contexto doméstico ou escolar.

Segundo Kaplan, Sadock e Grebb (2003) exemplificam que as mesmas atitudes do TOD podem aparecer em outros transtornos, os sintomas mais frequentes observados em crianças com TOD; contudo, esse comportamento está presente tais como, transtorno de déficit de atenção/hiperatividade, transtornos cognitivos e retardo mental, entre outros.

De acordo com Barletta (2011), uma das dificuldades para a realização de uma boa avaliação diagnóstica do transtorno, é o fato de não existir um padrão de testes e inventários com respostas bem mais precisas sobre o transtorno, tendo consequência, a manipulação clínica torna-se uma estratégia básica para obter os dados. Rangé (2011) cita que, apesar de vários autores mencionarem diversas descobertas de ordem neurobiológicas associadas aos transtornos disruptivo, ainda não há como comprovar o diagnóstico tanto do TOD ou do TC por meio de exames físicos, pois os exames ainda não estão disponíveis.

Em relação aos fatores sociais vivenciados e apontados como causa do TOD, Teixeira (2014) menciona que não existe uma definição precisa dos padrões sociais; mas, as pesquisas apontam para um possível desencadeamento do transtorno nas famílias de baixo nível socioeconômico, as que vivenciam violência doméstica e com moradia localizada em setores de autos níveis de criminalidade. Como Barlow e Durand (2015) enfatizam sobre as influências sociais, bem como as interpessoais, sendo bem significativo devido afetarem intensamente a biologia do indivíduo, como também os transtornos psicológicos. Exemplos desse fato são: pais ausentes, abusadores, agressores, alcoólatras ou usuários drogas, ou que não impõem limites aos filhos.

Quanto maior o número, a gravidade e a complexidade dos atos, maior é a chance do Transtorno evoluir para a idade adulta, salienta, Robbins, Tipp \& Przybeck, (1991), podendo enfim concretizar o transtorno de conduta que acontece quando entram no amadurecimento da personalidade adulta.

Já Kazdin (1995), confirma em seus estudos, o papel da família e as suas características, sugere que quanto mais o comportamento familiar for tubuloso, apresentarão também essas atitudes antissociais ou agressivas e pior será prognóstico da criança quando se tornar adulta. 
A posição que a família exerce no contexto social é bastante relevante, uma vez que ela representa o primeiro ambiente social e comportamental em que 0 indivíduo foi inserido. GAUER; VASCONCELLOS; DAVOGLIO (2012) cita que a família, é vista como um sistema sócio afetivo básico e vital na vida da criança, exercendo significativamente um grande impacto no seu desenvolvimento individual, tanto no comportamento e na construção da sua personalidade. Para entendermos melhor do funcionamento do comportamento antissocial na infância e adolescência, é importante que se considere a possibilidade de que as vivências e as experiências familiares possuem relação direta com tal tipo de conduta.

Sendo muito importante o papel familiar estando esclarecido e que acompanha a criança, estar sempre atenta a qualquer nova atitude e venha ajudar o filho, mostrando-Ihe o outro lado, ao invés de ser duro e apático, tratá-lo com mais afabilidade e ensinando a empatia pelo próximo.

\title{
3 Como reagem as crianças acometidas por Transtorno Opositor Desafiador
}

Esse transtorno por um distúrbio que acomete crianças e adolescentes, está caracterizado por perturbações e conflitos com os outros, dificuldade em seguir regras, normas morais e autoridades, além da dificuldade em socialização. E as crianças com as características do transtorno são muito desobedientes, solitários, além de serem hostis, desafiando constantemente seus pais, seus professores e outras pessoas que podem remeter qualquer outro tipo de autoridade.

É bastante comum também a dificuldade em controlar as emoções, muitas vezes com ataques de fúria, com verbalizações agressivas, hostilidades e também serem vingativos. E em geral caracteriza-se pelos seguintes sintomas:

\begin{abstract}
... um padrão global de desobediência, desafio e comportamento hostil. Os pacientes discutem excessivamente com adultos, não aceitam responsabilidade por sua má conduta, incomodam deliberadamente os demais, possuem dificuldade de aceitar regras e perdem facilmente o controle se as coisas não seguem a forma que eles desejam. (SERRAPINHEIRO et al. 2004, p. 273).
\end{abstract}

Crianças e adolescentes com o esse transtorno desafiam as regras sociais e morais e também tendem a perturbar deliberadamente quem as rodeiam, manifestam seu descontrole emocional em apenas um ou mais ambientes, como escola, casa, casa de amigos e familiares. 
A criança portadora do transtorno tende a efetuar uma forma de agressão emocional, na qual tenta agredir seus familiares, agindo de forma oposta do que the pedem. Assim causa mais sofrimento àquelas que a cercam do que à própria criança, pois acha que está certa em suas atitudes agressivas e não as evita, pois não são atitudes intencionais. Ballone (2002) em seu estudo é expressamente claro, pois o conjunto de atitudes de agressão que podem aparecer nos casos de TDO é extenso e pode variar de acordo com as características de cada comportamento familiar. A criança se manifestar não apenas sob a forma de atitude no sentido de agredir, mas, também em comportamentos como o silêncio, a omissão, a apatia e até fazendo pouco caso.

Segundo Ballone (2002, p. 3-4), "A maior evidência que os comportamentos opositores são agressivos, na medida em que causam o mal-estar emocional no outro, é a ausência dele, na ausência deles se quer agredir", sentem gosto ao ver a reação nervosa do outro, caso se sentir que não aconteceu assim, acontece os ataques de fúria.

\section{Importância de conhecer e entender como essas crianças com TOD reagem na escola}

Os prejuízos durante a aprendizagem da criança com TDO são grotescos, como elucida Teixeira (2014), as reprovações se tornam muito mais frequentes na vida escolar. Onde problemas de relacionamentos, geralmente entre estudantes em sala de aula e prejuízos acadêmicos estão relacionados com aumento de agressividade e de comportamentos de suas condutas pessoais. Cita também, em relação à avaliação:

Aponta ser importante a observação do desempenho escolar comprometido por frequentes reprovações. De fato, trata-se de um dos indicativos do TDO. O autor alerta para o padrão de comportamento da criança na escola, a interação social com os colegas, os professores e os demais funcionários da instituição. As características relevantes para o diagnóstico, segundo o autor, estão relacionadas a um histórico de desobediência e de desafio à autoridade de professores e funcionários, às ações impulsivas e aos constantes conflitos com os colegas de sala de aula. Também a recusa em pedir ou aceitar ajuda, principalmente dos professores, e a recusa em reconhecer ou aceitar a culpa, atribuindo-a sempre a outrem, devem ser levadas em consideração. (TEIXEIRA, 2014, p.50) 
A criança agressiva geralmente não atende aos comandos do professor, não participa dos trabalhos em grupo e quando o professor propõe dinâmicas pedagógicas se ela não sair vencedora ou como uma dos melhores participantes, não aceita a derrota e acaba ficando enraivecida. Essas pequenas frustrações podem provocar um comportamento indisciplinado, levando a agressões e maus tratos.

O seu comportamento se torna um grande impedimento para que a criança venha construir seu conhecimento, pois ela não pede e nem aceita a ajuda do professor. O professor então necessita utilizar-se de técnicas para conseguir ganhar a confiança do seu aluno e trazê-lo para perto de si. Segundo Vergés e Sana (2012, p.18):

O professor deve usar a sua autoridade dentro dos limites da democracia para orientar seus alunos, pois quanto maior a confiança entre eles, mas bem aceitas serão as intervenções do professor. Assim, este deve dizer "sim" sempre que possível e "não" quando necessário, para que passe confiança aos alunos e, assim eles possam se sentir mais seguros e confortáveis na promoção de diálogo com o professor.

O processo para o ensino-aprendizagem desse aluno se torna assim, mais lento que o do restante da turma, pois ele não consegue seguir os comandos do professor quando é necessário. Teixeira $(2014$, p. 35) completa:

Essas crianças apresentam maior agressividade, maior impulsividade, mais conflitos com outros estudantes, maior dificuldade nos relacionamentos sociais e pior desempenho acadêmico. Essa associação piora o prognóstico de tratamento e pode ainda facilitar a evolução do transtorno desafiador opositivo para o transtorno de conduta.

Quando o conteúdo trabalhado pelo professor não desperta seu interesse, ele inventa qualquer outra distração e não prestar atenção, se ele não quer estudar, apenas não o faz, quando na sala tem regras, essa criança apresenta uma grande dificuldade em ouvir, prestar atenção ao professor e a realizar suas tarefas.

A falta de regras, limites e a falta de rotina é um impasse para o aprendizado da criança com transtorno opositor desafiador, pois ela não possui horário para a realização das tarefas escolares, e quando a faz é de qualquer jeito, por não ter o acompanhamento necessário, muitas vezes devido à ausência dos pais. Ficando assim cada vez mais difícil a concretização de um aprendizado mais efetivo e sólido na vida escolar dessa criança. 
Algumas sugestões dos autores podem ajudar não só profissionais da educação, mas também os pais dos alunos acometidos com o TOD, sugerindo a busca de informações sobre o transtorno, antes mesmo de iniciar alguma intervenção pedagógica, pois o professor precisa de fato conhecer o tipo de transtorno que seu aluno possui. Os autores Castro e Nascimento (2009) propõem ações em diálogo com o aluno, além de outras sugestões para o trabalho em sala de aula:

Orientação para família que buscam por ajuda;

Manter encontros frequentes entre profissional de saúde mental com a família;

Manter contato com especialistas da escola ou que estejam em contato com o aluno;

Ter paciência extra;

Incentivar elogios ao aluno quando conseguir se comportar ou realizar algo;

Deixar que sente-se próximo a seu professor e seus colegas afetivos;

Evitar distrações com janelas, portas ou coisas;

Deixar regras e acordos, explícitos e bem visíveis;

Estabelecer contato com a criança pelo olhar;

Falar baixo, de forma gentil e afetuosa;

Dar orientações curtas e claras;

Dividir as tarefas complexas em várias partes, com orientações mais simples;

Esperar pela resposta do aluno, ao seu tempo;

Repetir as ordens sempre quando necessário;

Ensinar o aluno a usar a agenda;

Estabelecer metas individuais;

Alternar métodos de ensino, evitando aulas repetitivas;

Fazer o aluno ser ajudante do professor;

Deixar o aluno sair alguns instantes da sala, quando muito agitado;

Possibilite o uso de equipamentos eletrônicos e multimídias.

As sugestões são precedidas pela premissa de que só o professor não pode atuar só, pois precisa fazer parte de uma equipe multidisciplinar preparada aos vários aspectos e abordagens para reintegrar o aluno ao convívio escolar mais amigável. 
Outras sugestões de intervenção sobre as adaptações organizacionais que o professor pode fazer em sala de aula. Segundo Brasil (2002):

É necessário que o professor estabeleça claramente, os limites necessários para a convivência da turma inteira;

É fundamental que identifique a forma mais adequada de comunicação para cada aluno, que permita que ele trabalhe com compreensão, com prazer e mais autonomia possível;

É importante que o ensino seja individual, quando necessário, guiado por um Plano de Ensino voltado para as necessidades educacionais especiais do aluno;

É importante que o aluno possa relacionar o que está aprendendo com as situações de sua vida cotidiana;

Prever e anteceder ações que diminua a ansiedade do aluno que apresenta comportamento agitado.

Como cita Brasil (2002, p. 19), "Assim, é importante que o professor estruture o uso do tempo, do espaço, dos materiais e a realização das atividades, de forma a diminuir ao máximo o caos que um ambiente complexo pode representar para esse aluno".

A importância das sugestões acima é que usem o Plano de Ensino, pois é um subsídio do governo Federal com distribuição gratuita para todo o país, e que dessa maneira, esse material seja acessível para todos os profissionais que vão os atender e também os pais que necessitarem de mais informações. Afinal segundo Serrano (2015) se a atuação do profissional da educação é fundamental, dos pais também é; e a orientação e aconselhamento familiar, que os preparar para ajudar pacientemente a criança com as tarefas escolares e cotidianas.

Vale lembrar, de acordo com Rosa (2005):

A educação inclusiva é uma prática inovadora que está enfatizando a qualidade de ensino para todos os alunos, exigindo que a escola se modernize e que os professores aperfeiçoem suas práticas pedagógicas. É um paradigma que desafia o educador a aprender mais sobre a diversidade humana a fim de compreender os diferentes modos de cada ser humano ser, pensar, sentir e agir. (ROSA, 2005, p.12)

O professor é antes de tudo um profissional que se formou para isso, portanto vai fazer o melhor trabalho que for possível; no seu dia a dia, lida com o diferente, com as dificuldades e diversidades que a vida os apresente. $\mathrm{E}$ se a 
sociedade é assim tão diversificada, a sala de aula também é vista assim, uma é reflexo da outra.

A inclusão dos alunos com necessidades educacionais especiais, seja o TOD, ou qualquer outro nas turmas do ensino regular da educação é fundamental, porque se eleva a consciência de cada um dos atores presentes no processo, seja o próprio professor, quanto à comunidade escolar, quanto os pais, colegas, em relacionar a escola cada vez mais à vida, já os benefícios que todos partilharão serão importantes para a formação das crianças e adolescentes e para que os adultos vivam a experiência da inclusão, e uma inclusão de fato que aconteça em sociedade, começando na escola.

E, com a experiência da inclusão, acontece com um ganho de consciência e de humanidade, respeito e afeto pelos alunos portadores de qualquer transtorno ou especialidade educacional, a inclusão geralmente muda o ambiente e as pessoas ao redor, nos transforma um pouco melhor e mais sensíveis a dor do outro, um pouco menos apático.

\section{Importância de tratar o Transtorno Opositor Desafiador}

A orientação é que o tratamento deve ser multidisciplinar, abordando diferentes áreas e também métodos, considerando tudo sobre a avaliação e orientações de como agir nos ambientes sociais e familiares aos quais essas crianças estão inseridas, incluindo o ambiente escolar.

Segundo Rangé et al (2011) estando de acordo com o tema, Teixeira (2014) esclarece que a evolução do TOD são variáveis, onde em estatística, $67 \%$ das crianças que são diagnosticadas com o transtorno desafiador opositor, quando acompanhadas terapeuticamente, deixarão de apresentar os sintomas do transtorno nos anos posteriores e que $30 \%$ dessas diagnosticadas com TOD, sem tratamento poderão intensificar os sintomas, evoluindo para o TC na adolescência.

Corroborando com o conteúdo do DSM-5, Teixeira (2014) elucida que, nas crianças em que os sintomas do TOD se manifestam antes dos oito anos de idade, caso não seja tratado por um profissional competente, poderá ser maior o risco de evoluir para o TC. 
Cita Rangé et al, (2011) elucida que caso não haja um tratamento eficaz, o indivíduo que não recebe tratamento, o risco de evoluir para o TC poderá acontecer em até $75 \%$. Teixeira (2014) menciona que, após a evolução para o TC, e uns $10 \%$ delas poderão evoluir para o Transtorno de Personalidade Antissocial, resposta mais severa para o indivíduo.

Quando a criança também apresenta outros transtornos mentais associados, como ansiedade, TDAH, depressão e bipolaridade, o uso de medicamentos pode ser necessário. Podendo fazer o uso mesmo durante o tratamento do TOD, conforme afirma Teixeira (2014):

...é comprovada a eficácia de alguns medicamentos, segundo estudos científicos realizados nessa área. O foco de atuação desses medicamentos está relacionado à diminuição dos sintomas de impulsividade, raiva e agressividade, característicos do transtorno. O autor alerta, porém, que tais medicamentos atuam como paliativos, aliviando alguns desses sintomas e proporcionando uma melhora do quadro comportamental da criança com 0 TDO. Essa melhora desemboca em um aumento da qualidade de vida não só da criança, como também da família e de outras pessoas com as quais o paciente interage. (Agostini, Santos, 2017, p. 24 et al Teixeira, 2014)

Com o tratamento certo, é possível controlar os sintomas do transtorno de oposição desafiante e com da psicoterapia, a criança ou o adolescente aprende a controlar suas próprias emoções, e a lidar com as frustrações e relacionar-se socialmente melhor.

Para os pais, a terapia familiar e as orientações do psicólogo ajudam a elaborar melhores métodos de disciplina e como agir diante de atitudes de falta de controle emocional. Sobre a importância da utilização da terapia familiar, Gauer, Vasconcellos e Davoglio (2012) afirma:

Assinalam que o uso, no contexto familiar, de práticas educativas parentais com a finalidade de promover a socialização dos filhos é importante. Contudo, essas práticas nem sempre resultam em reações sólidas, devido ao fato de estarem vinculadas às emoções, à subjetividade, às perspectivas e às dificuldades apresentadas pelos pais. Os autores chamam a atenção para os estudos nessa área, que evidenciam que tais práticas educativas parentais se encontram fortemente associadas aos comportamentos antissociais emitidos pelos filhos, uma vez que, por meios delas, às vezes indiretamente, os pais instigam a repetição desses comportamentos, justamente pela incoerência da disciplina utilizada e por uma interação positiva deficiente. 
(Agostini, Santos, 2017, p. 22 et al Gauer, Vasconcellos e Davoglio, 2012)

É necessário rememorar que o sucesso do tratamento depende das mudanças que devem ocorrer nos ambientes familiares e sociais que convive a criança; dependendo disso os resultados podem demorar aparecer e o tratamento levar até anos a mostrar resultados relevantes.

Teixeira (2014) refere a psico-educação escolar e as intervenções sendo fundamentais no tratamento da criança com um TOD, segundo o autor, objetiva a orientação aos professores, orientadores pedagógicos, diretores e demais funcionários da instituição escolar, para possibilitar a gestão correta dos sintomas do transtorno no ambiente escolar, essencial para o sucesso do tratamento e facilitar todo o olhar sobre as crianças que são acometidas por ele.

Já em relação às intervenções por meio escolar, Teixeira (2014) afirma:

...que elas objetivam que professores e funcionários tenham possibilidade de acionar os mecanismos adequados, a fim de que haja a devida reintegração do aluno em sala de aula e no contexto escolar como um todo. (Agostini, Santos, 2017, p. 23 et al Teixeira, 2014)

Visando ajudar, segundo o autor, podem ser aprendidas técnicas comportamentais muito importantes, com a finalidade de promover e estimular comportamentos aceitáveis para serem introduzidos, bem como desencorajar os comportamentos agressivos e o de desrespeito por parte do aluno, perante qualquer outro personagem escolar, tornando-os mais afetivos e mais sociáveis.

\section{Considerações Finais}

O transtorno aqui abordado nos apresenta um alto nível de intolerância e agressividade como uma de suas consequências principais, podendo chegar à evolução ao caso dos Transtornos de Conduta, quando não é descoberto e tratado desde a infância, podendo ser comparado com outros transtornos.

Como verificado na pesquisa, a compreensão sobre o transtorno desafiador opositor é de fundamental importância, uma vez que tal transtorno constitui um grave problema tanto para a dinâmica familiar, quanto para a vida educacional e social da criança e do adolescente. O comportamento agressivo constitui-se em uma gama de atitudes bastante desastrosas. 
São inúmeros os estudos que têm abordado sobre o transtorno opositor desafiador, tentando aprimorar o tratamento e a prevenção, assim como o processo de avaliação e tratamento das condutas agressivas nessas fases da vida e muitos deles tem realmente contribuído de forma eficaz para o alcance desses objetivos em tratar o transtorno.

O meio social e ambiente familiar em que convivem são variáveis que influenciam na expressão da agressividade em maior ou menor grau. Reconhecer como cada um desses fatores interfere na formação da agressividade propiciando a intervenção e a prevenção de formas adequadas; podendo evitar falha no tratamento do transtorno opositor desafiador, que pode diminuir o nível de violência nas escolas, nas famílias e em qualquer outro ambiente que possa frequentar.

E, na educação formal que acontece dentro da escola, onde deve estar com toda sua equipe instruída e preparada ao bom atendimento; a equipe multifuncional e todo seu corpo escolar esclarecido e aberto a um bom diálogo com a criança com TOD, para dar melhor apoio e saber como estarem atuando com este tipo de transtorno, dar suporte ao professor que é quem vai estar mais tempo à frente da convivência dentro da sala de aula com os colegas, reforçando e ajudando no cumprimento de regras, limites e consequentemente uma melhor conduta social.

Enfim, é importante e responsabilidade de todos os atores envolvidos, conhecer, para compreender e aprender como agir e conviver com essas crianças, a fim de torná-las mais apáticos e também se sentirem mais compreendidos e amados. 


\section{REFERÊNCIAS BIBLIOGRÁFICAS}

AGOSTINI, V. L.M. L., SANTOS, W.D.V. Transtorno Desafiador De Oposição E Suas Comorbidades: Um Desafio Da Infância À Adolescência. Psicologia. ptISSN 1646-6977 Documento publicado em 25.02.2018. Disponível em: https://www.psicologia.pt/artigos/textos/A1175.pdf Acessado em 14/01/2021.

American Psychiatric Association (APA) (2002). DSM-IV-TR, Manual Diagnóstico e Estatístico de Transtornos Mentais (4aㅡ ed. texto revisado). Washington, DC: APA. [ Links ]

BARLETTA, Janaína Bianca. Avaliação e intervenção psicoterapêutica nos transtornos disruptivos: algumas reflexões. Rev. bras. ter. cogn. Vol 7 n.2 Rio de Janeiro-dez.2011.

Disponível em: <http://pepsic.bvsalud.org/scielo.php?script=sci_arttext\&pid=S18086872011000200005> Acesso em: 15.01.2020.

BALLONE G.J. A família faz mal a Saúde? - in Psiqweb Psiquiatria Geral,Internet, atualizado em 2002. Disponível: http://sites.uol.com.br/gballone/familia/fazmal.html Acesso em: 24/09/2019.

BARLOW, D.H; DURAND, M.V. Psicopatologia - uma abordagem integrada. Tradução da quarta edição norte-americana. São Paulo: Cengage Learning, 2008.

BARROS, P; SILVA, F.B.N. Origem e manutenção do comportamento agressivo na Infância a e adolescência. Rev. Bras. Ter. Cogn. v.2 n.1 Rio de Janeiro jun. 2006.

BRASIL. Alunos com necessidades especiais. Disponível em http://portal.mec.gov.br/seesp/arquivos/pdf/diretrizes.pdf. Acesso em 21/12/2019.

CABALLO, Vicente E.; SIMÓN, Miguel Ángel. Manual de psicologia clínica infantil e do adolescente: transtornos específicos. 1 ed. Reimpr. São Paulo: Santos, 2015, p.460

CASTRO, C. A. A.; NASCIMENTO, L. TDAH: Inclusão na Escola: Adequação a Classe Regular de Ensino para Alunos Portadores de TDAH (Transtorno de Déficit de Atenção / Hiperatividade). Rio de Janeiro: Ciência Moderna, 2009. CARRARA, HELIO HUMBERTO; DUARTE, GERALDO. Semiologia Obstétrica. Medicina (Ribeirão Preto. Online), v. 29, n. 1, p. 88-103, 1996.

ENKIN, MURRAY et al. Guia para a atenção efetiva na gravidez e no parto. 3 ed. Rio de Janeiro: Guanabara Koogan, 2005.

LOPES, ANTONIO CARLOS. Tratado de Clínica médica. São Paulo: Roca, 2006.

GAUER, Gabriel J. C.; VASCONCELLOS, Silvio J. L.; DAVOGLIO, Tárcia R. Adolescentes em Conflito: violência, funcionamento antissocial e traços de psicopatia. São Paulo: Casa do Psicólogo, 2012, 236 p. 
GUSSO, GUSTAVO; LOPES, JOSÉ MAURO CERATTI; DIAS, LÊDA CHAVES. Tratado de Medicina de Família e Comunidade: Princípios, Formação e Prática. 2ª̣edição. Artmed, 2018.

JUNIOR, AULER; COSTA, JOSÉ OTÁVIO; YU, LUÍS. A Série Manual do MédicoResidente do Hospital das Clínicas da Faculdade de Medicina da Universidade de São Paulo (HCFMUSP), em parceria..[Apresentação]. Medicina de família e comunidade [S.I: s.n.], 2017.

KAPLAN, H. I.; SADOCK, B. J. Compêndio de Psiquiatria: Ciências do Comportamento e Psiquiatria Clínica. 9 ed. Porto Alegre: Artmed, 2007, 1172 p.

KAPLAN, H I.; SADOCK J.; GREB. A. Compêndio de Psiquiatria: Ciências do comportamento e Psiquiatria Clínica. 7. ed. 3. reimpressão. Porto Alegre: Artmed, 1997.

Kazdin, A. E. (1995). Conduct Disorder in childhood and adolescence. Newbury Park: Sage. [ Links ]

LUISELLI, J.K. Características clinicas e tratamento do transtorno desafiador de oposição. In : V. E. Caballo e M. Simon (Orgs.). Manual de psicologia clínica infantil e do adolescente: Transtornos específicos São Paulo: Santos, 2005. (p. 39- 55).

MARINHO M. L; CABALLO; V.E. Comportamento anti-social infantil e seu impacto para a competência social. Psicologia, Saúde e Doenças, 2002, 3 (2), 141-147.

RANGÉ, B. (org.) (2001). Psicoterapias Cognitivo-comportamentais: Um diálogo com a Psiquiatria. Porto Alegre; Artmed, 2001

RANGÉ, B... [et al.]. Psicoterapias cognitivo-comportamentais: um diálogo com a psiquiatria. $2^{\circ}$ Ed. Porto Alegre: Artmed, 2011.

Robbins, L. N.; Tipp, J. \& Przybeck, T. (1991). Antisocial personality. Em: L. N. Robins \& D. A. Reegier (Orgs.). Psychiatric disorders in America (pp.51-59). Nova York: The Free Press. [ Links ]

ROSA, C.C. Os limites da Inclusão. Revista Pátio. Porto Alegre, ano III, n. 32, p.08-12, nov. 2004/ jan. 2005.

SERRA-PINHEIRO, M. A., SCHIMITZ, M., MATTOS, P. et al. Transtorno desafiador de oposição: uma revisão de correlatos neurobiológicos e ambientais, comorbidades, tratamento e prognostico. Revista Brasileira de Psiquiatria, v.26, n.4, p273-276. Dez. 2004

SERRANO. Alan Indio. Transtornos hipercinéticos e déficit de atenção. Disponívelemhttp://portalses.saude.sc.gov.br/phocadownload/Regulacao/protocolos/ 31\%20Transtornos\%20hipercin\%C3\%A9ticos\%20e\%20d\%C3\%A9ficit\%20de\%20ate n\%C3\%A7\%C3\%A3o.pdf. Acesso em: 26/12/2020. 
SILVA, T. C. G. Transtorno Opositor Desafiador - Como Enfrentar O Tod Na Escola. Rio de Janeiro - RJ Universidade Cândido Mendes 2017. https://www.avm.edu.br/docpdf/monografias publicadas/posdistancia/53309.pdf Acesso em: 14 de janeiro de 2020.

TEIXEIRA, Gustavo. O Reizinho da Casa: manual para pais de crianças opositoras, desafiadoras e desobediente. 1 ed. Rio de Janeiro: Best Seller, 2014, $108 \mathrm{p}$.

\section{3.}

Manual dos transtornos escolares. Rio de Janeiro: Editora BestSeller,

VERGÉS, Maritza Rolim de Moura; SANA, Marli Aparecida - Limites e indisciplina na educação infantil. 3ํe. ed. São Paulo: Alínea, 2012.

Webster-Stratton, C. \& Hebert, M. (1994). Troubled families: Problem Children. Chichester: Wiley. [ L Links ]

BRITES, Luciana. Entenda o que é o Transtorno Opositor - TOD. Revista NeuroSaber. 2016. Disponível: https://neurosaber.com.br/entenda-o-que-e-otranstorno-opositivo-desafiador-tod/ Acesso em 13 de Novembro de 2020. 